\title{
Contribution of EFAST Ultrasound in the Management of Chest and Abdomen's Blunt Trauma in the City of Parakou, Benin
}

\section{Tchaou Blaise Adelin ${ }^{*}$, Savi De Tovè Kofi-Mensa ${ }^{2}$, Tchégnonsi N’vènonfon Charles Frederic ${ }^{1}$, Gandji Elohonnan Wilfred ${ }^{3}$, Ngamo Deugoue Gabriel Marie ${ }^{2}$, Allodé Salako Alexandre ${ }^{4}$}

\author{
${ }^{1}$ Department of Anesthesia, Resuscitation and Emergency, CHUD, Parakou, The Republic of Benin \\ ${ }^{2}$ Department of Radio-Diagnostic and Medical Imagery, CHUD, Parakou, The Republic of Benin \\ ${ }^{3}$ Department of Visceral Surgery, National Teaching Hospital-HKM, Cotonou, The Republic of Benin \\ ${ }^{4}$ Department of General Surgery, CHUD, Parakou, The Republic of Benin \\ Email: *tchblaise@yahoo.fr
}

How to cite this paper: Adelin, T.B., De Tovè Kofi-Mensa, S., Frederic, T.N.C., Wilfred, G.E., Marie, N.D.G. and Alexandre, A.S. (2020) Contribution of EFAST Ultrasound in the Management of Chest and Abdomen's Blunt Trauma in the City of Parakou, Benin. Open Journal of Anesthesiology, 10, 388-407.

https://doi.org/10.4236/ojanes.2020.1011035

Received: September 22, 2020

Accepted: November 16, 2020

Published: November 19, 2020

Copyright $\odot 2020$ by author(s) and Scientific Research Publishing Inc. This work is licensed under the Creative Commons Attribution International License (CC BY 4.0).

http://creativecommons.org/licenses/by/4.0/ (c) (i) Open Access

\begin{abstract}
Background: Blunt thoracic and abdominal traumas are frequent and have a poor prognosis in the absence of prompt diagnosis and adequate management. An ultrasound performed in the emergency room allows a precise diagnosis and a better orientation of the victims. Objective: To assess the contribution of EFAST ultrasound in the management of blunt thoracic and abdominal traumas. Patients and method: Cross-sectional descriptive and analytical study with prospective data collection carried out from February $20^{\text {th }}$ to August $20^{\text {th }}, 2017$ in the emergency and intensive care units of the Parakou University Hospital Centre. An ultrasound machine fitted with a 3.5 $\mathrm{MHz}$ convex probe was used to search for post-traumatic effusion by the EFAST technique on admission and then as needed over 24 hours and after surgery. Results: Sixty-three patients were collected with an $85.71 \%$ male predominance. The average age was $31.36 \pm 13.29$ years. The time to perform the EFAST ultrasound was $7 \pm 3 \mathrm{~min}$. EFAST was positive in $50.79 \%$ of patients. Five patients $(7.93 \%)$ received emergency treatment for hemodynamic instability and positive EFAST within an average of $3.46 \pm 2$ hours. Eighteen patients (27.58\%) received after monitoring by EFAST, surgery within 9 hours 12 minutes (hemoperitoneum) and 27 hours 58 minutes (hemothorax). Two patients were tested positively for EFAST after surgery. Conclusion: The introduction of an EFAST ultrasound as a sorting tool in an environment with limited resources is desirable and feasible.
\end{abstract}

\section{Keywords}

Emergencies, Blunt Trauma, EFAST, Thorax, Abdomen 


\section{Introduction}

Chest and abdomen injuries are recurrent and represent a major cause of morbidity and mortality [1] [2]. $20 \%$ to $25 \%$ of trauma victims die of thoracic injuries [3]. Moreover, $20 \%$ of road accident victims have abdominal trauma [4] and $4.3 \%$ pass away of it [5].

In developed countries, the creation and performance of pre-hospital medicine, thanks to the Emergency Medical Assistance Service (SAMU), revolutionized trauma patients care [6]. Initially, performed by radiologists, the search for post-traumatic fluid effusions by ultrasound was gradually integrated into emergency exploration protocols, relegating Diagnosic Peritoneal Lavage (DPL) to rare indications [7]. Since the 1990s, ultrasound has quickly established itself as a quick bedside exam. Several studies, carried out in North America have shown that ultrasound performed by emergency surgeons was not only feasible [8] [9] [10] [11] but above all that it made it possible to quickly confirm a lesion with good sensitivity and good specificity [7]. During the same period, many emergency services acquired ultrasound machines. Thus, several attempts at standardization have led to the development of a protocol: FAST (Focussed Abdominal Sonography for Trauma patients) [12]. This is a protocol for coding emergency ultrasound for trauma patients, especially abdominal, in a synthetic, oriented and simple way. In the 2000s, in the United States, it is believed to have replaced peritoneal lavage in the diagnosis of hemoperitoneum. Since then it has continued to be promoted and is now taught as part of Advanced Trauma Life Support on the North American continent (North American Trauma Management Protocol). In the mid-2000s, the chest assessment for pneumothorax and hemothorax has been added to the traditional FAST examination, resulting in the acronym EFAST (Extended FAST), "extended FAST" to the pleura [13] [14].

Ultrasound using the EFAST technique has played a central role in this management [15]. In fact, from the place of the accident, it is possible to prioritize the degree of emergency [16] and thus it becomes an extension of the emergency physician's hand and his ultrasound stethoscope assesses the pleura, the peritoneum [17] [18] and pericardium [19] with the advantage of being rapid (less than 5 minutes), non-invasive and repeatable. In developing countries, the lack of pre-hospital care, the under-equipment of health facilities and the lack of qualified human resources limit the sorting of trauma patients [20]. In black Africa particularly, the management of chest and abdomen trauma remains a real challenge. The diagnosis of thoracic and abdominal lesions, which has become easy thanks to the development of medical imaging (ultrasound and computed tomography), is further reduced to the simple performance of a standard $\mathrm{X}$-ray and an ultrasound in only $20 \%$ to $30 \%$ of cases [21] [22] [23]. In this context, puncture lavage of the peritoneum (PLP) is often the first resort in a suspected intra-abdominal lesion [24]. Very few studies have been published on ultrasound scans performed in emergency rooms in a resource-limited medical environment. Muller et al. in Congo agreed in 2015 that the introduction of 
FAST ultrasound was possible and necessary [25]. Can EFAST ultrasound improve the management of a blunt thoracic and abdominal trauma in the city of Parakou in Benin? This study was initiated to address the concern and its objective was to evaluate the contribution of EFAST ultrasound in the management of a blunt thorax and abdomen trauma.

\section{Patients and Method}

- Study framework

The study was carried out in the Department of Anesthesia-Resuscitation and Emergency (SARU) and the Department of Radio-diagnostic and Medical Imaging (DRMI) at the Departmental University Hospital of Parakou.

- Study method

Type and period of study: This was a cross-sectional study with a descriptive and analytical aim with prospective collection of data carried out over a period of six (06) months (February 20 to August 20, 2017) and which the protocol was submitted and validated by the ethics committee of the Faculty of Medicine of the University of Parakou.

Study population: The study concerned all patients suspected of a blunt thoracic and/or abdominal trauma, multiple trauma or not admitted to the emergency department and hospitalized in intensive care during the study period. We considered as closed traumatized of the thorax and/or the abdomen any patient admitted for trauma in whom the questioning and the physical examination found signs related to a thoracic and/or abdominal damage without solution of continuity of the thoracic or abdominal wall.

Inclusion criteria: were included: All patients with a blunt trauma related to thorax and/or abdomen and from whom we have obtained free and written consent to participate in the study or from a close relative.

Non-inclusion criteria: patients with open trauma related to the thorax and/or open abdomen trauma and patients who died after admission were not included.

Exclusion criteria: Patients with non-traumatic effusion and those in whom EFAST could not be performed were excluded from the study. Sampling technique: We performed a thorough recruitment of all patients fulfilling the inclusion criteria.

Variables studied:

Dependent variable: The dependent variable is represented by the result of the EFAST ultrasound. It is a dichotomous dummy variable which modalities are: positive or negative depending on the presence or not of effusion on EFAST.

Independent variables

Sociodemographic data: age, sex, profession.

Clinical data:

- Anamnestic data: time of admission, mode of admission, mode of transport, causes of trauma, mechanism of trauma.

- General signs, search for vital distress (cardiocirculatory distress, respiratory, 
neurological and metabolic distress and evaluation of severity scores: Revised Trauma Score (RTS): scored from 0 to 12 and Injury Severity Score (ISS): next to 1 to 75$)$.

- Looking for clinical signs of effusion: These are signs in favor of pleural fluid or gas effusion and signs in favor of peritoneal fluid effusion suspected on physical examination. These are dichotomous nominal qualitative variables whose modalities depend on the presence or absence of physical signs of effusion.

- Lesion assessment: These are lesions retained after complete exploration of the patient (clinical, paraclinical and operative assessment).

Paraclinical data:

- Imaging: ultrasound results of the chest and abdomen and standard x-rays of the chest, pelvis and limbs.

- Biology: hemoglobin level, hematocrit level.

Therapeutic data

- Therapeutic decision: Surgical treatment (abdominal and thoracic surgery or monitoring.

- Peroperative diagnosis: hepatic, splenic, pancreatic, intestinal, mesenteric lesions, postoperative peritonitis, others.

- Nature of the liquid found: thoracic (blood, serosity, chyle, other) and Abdominal (blood, bile, pus, urine, chyle, other).

- Delay between performing the EFAST ultrasound and surgical management is a quantitative variable expressed in hours.

Evolving data

- Three modalities: the outcome may be favorable and/or unfavorable, or complicated by postoperative bleeding. The discharge method: transfer to surgical hospitalization unit, put in exit.

\section{Collection of Data}

All the subjects included underwent after admission and conditioning, a measurement of vital parameters, a physical examination and an EFAST ultrasound and, as appropriate, clinical monitoring and EFAST ultrasound monitoring. The data was collected using: a survey sheet containing the variables to be studied. EFAST ultrasound was systematically performed in all patients by a radiologist using a "General Electric Logiq $100^{\odot \text { ” }}$ brand portable ultrasound system with a $3.5 \mathrm{MHz}$ convex abdominal probe. In some cases, it had made it possible to diagnose certain lesions. Paraclinical work-ups were performed in patients awaiting surgery and in patients undergoing surveillance during observation. The EFAST ultrasound operation was performed after 30 minutes, one hour, two hours, eight hours and twenty-four hours of observation, then every 24 hours after which the decision to surgery, to continue monitoring, hospitalization or even discharge were taken by the surgeon in collaboration with the resuscitator. EFAST ultrasound was performed in all patients after surgury every 24 hours until discharge. 


\section{Data Processing and Analysis}

The data were coded and analyzed using EPI INFO software. Data were entered and analyzed using Epi Info software version 3.5.4 and 7.1.1.14 from Center of Disease Control (CDC) respectively. The data analysis was carried out in two parts: A descriptive part which consisted of calculating the percentages for the qualitative variables and the averages and standard deviation for the quantitative variables. An analytical component which consisted in measuring the association between the dependent variable and the independent variables. Statistical Chi-square, Fischer or Yates-corrected Chi-square tests were used as appropriate to determine the degree of significance of the association ( $\mathrm{p}$-value). The significance level was set at 0.05 .

\section{Results}

\section{Frequency}

During the study period, 1331 patients were admitted to the emergency department. We counted 546 trauma patients (41.02\%) among which 63 cases of closed trauma related to thorax and abdomen were collected, representing $11.53 \%$ of admissions and divided into 14 thorax related trauma patients (22.22\%), 20 abdominal trauma (31.75\%) and 29 thoraco-abdominal trauma (46.03\%). Among the 63 patients, we counted 45 polytrauma victims (71.42\%).

\section{Sociodemographic data}

In our series, 54 traumatized (85.71\%) were male and 9 (14.29\%) female with a sex ratio of 6 . The mean age of the patients was 31.36 years \pm 13.29 years with extremes of 9 years and 69 years. The 20 to 40 age group was the most represented. The different socio-professional categories objectified in our series were: 40 independent workers (63.49\%), 17 students and pupils (26.99\%), 3 unemployed patients (04.76\%) and 3 Employees (04.76\%). Table 1 shows the Distribution of patients according to age, sex and profession.

\section{Clinical Data}

- Method of admission

Thirty-nine patients $(61.90 \%)$ were admitted to the emergency room directly from the place of accident and $38.1 \%$ of victims $(n=24)$ were referred from a health center after first aids.

- Consultation period

The median time to consultation was 2 hours and 50 minutes with extremes of 08 minutes and 83 hours (3.5 days).

- Transport modalities

In our series, 4 patients (6.35\%) benefited from medical transport versus 93.65\% ( $\mathrm{n}=59$ ) who were transported using makeshift means among which we found; motorcycles, $46.03 \%$ of cases $(n=29)$; public transport vehicles, $22.22 \%$ of cases $(\mathrm{n}=14)$; firefighter, $15.87 \%$ of cases $(\mathrm{n}=10)$; non-medical ambulances, $9.53 \%$ of cases $(n=6)$.

- Circumstances of the trauma 
The circumstances of trauma were varied. We identified 43 cases of accidents occurring on public roads (68.25\%), 10 cases of physical assaults (15.87\%), 7 cases of falling from the top of a tree (11.11\%), 1 case of a domestic accident (1.59\%), 1 case of a work accident (1.59\%) and 1 case of a sports accident (1.59\%).

- Physical examination data

In our series, 10 patients (15.87\%) had cardiocirculatory distress (hypovolemic shock state). On the other hand, respiratory distress was objectified in 23 cases $(36.51 \%)$. Table 2 shows the mean, standard deviation and extremes of general vital parameters.

\section{Scores of severity}

The Revised Trauma Score (RTS) and the Injury Severity Score (ISS) were assessed. The mean RTS was $10.93 \pm 01.41$ with extremes of 07 and 12. Six (06) chest related trauma or $09.52 \%, 07$ (11.11\%) abdominal trauma and $15(23,81 \%)$ thoraco-abdominal trauma patients had a score below 12 . The mean ISS was $20.73 \pm 14.40$ with extremes of 03 and 57. Table 3 shows the distribution of patients according to the results of the revised trauma. Score (RTS) and Injury

Table 1. Distribution of patients according to age, sex and profession.

\begin{tabular}{|c|c|c|c|c|}
\hline Variables & \multicolumn{4}{|c|}{ Sex } \\
\hline & \multicolumn{4}{|c|}{ Number/Percentage } \\
\hline Male & 54 & $(85.71)$ & \multirow{2}{*}{\multicolumn{2}{|c|}{$63(100)$}} \\
\hline Féminine & 9 & (14.29) & & \\
\hline \multicolumn{5}{|c|}{ Age and types of trauma } \\
\hline & Thorax & Abdomen & Thoraco-abdominal & Total \\
\hline \multicolumn{5}{|c|}{ Number/Percentage } \\
\hline $0-19$ & $3(4.76)$ & $3(4.76)$ & $5(7.94)$ & $11(17.46)$ \\
\hline $20-29$ & $4(6.35)$ & $9(14.29)$ & $5(7.94)$ & $18(28.58)$ \\
\hline $30-39$ & $2(3.17)$ & $4(6.35)$ & $15(23.81)$ & $21(33.33)$ \\
\hline $40-49$ & $2(3.17)$ & $3(4.76)$ & $2(3.17)$ & $7(11.10)$ \\
\hline$\geq 50$ & $3(4.76)$ & $1(1.59)$ & $2(3.17)$ & $6(9.53)$ \\
\hline Total & $14(22.22)$ & $20(31.75)$ & $29(46.03)$ & $63(100)$ \\
\hline \multicolumn{5}{|c|}{ Socio-professional categories and types of trauma } \\
\hline \multicolumn{5}{|c|}{ Number/Percentage } \\
\hline & Thorax & Abdomen & Thoraco-abdominaux & Total \\
\hline Independent workers & $7(11.11)$ & $11(17.46)$ & $22(34.92)$ & $40(63.49)$ \\
\hline Students and pupils & $6(09.52)$ & $6(09.52)$ & $5(07.94)$ & $17(26.98)$ \\
\hline unemployed patients & - & $2(03.17)$ & $1(01.59)$ & $3(04.76)$ \\
\hline Employees & $1(01.59)$ & $1(01.59)$ & $1(01.59)$ & $3(04.76)$ \\
\hline Total & $14(22.22)$ & $20(31.75)$ & $29(46.03)$ & $63(100)$ \\
\hline
\end{tabular}


Severity Score (ISS) and type of trauma.

Table 4 shows the distribution of patients according to the objectified effusions on physical examination and the site of the emergency trauma.

Table 2. Distribution of patients according to means, standard deviation and extremes of general vital parameters.

\begin{tabular}{ccc}
\hline Settings & Average & extreme \\
\hline Systolic blood pressure (mm Hg) & $104.47 \pm 20.41$ & $50-130$ \\
Heart rate $(\mathrm{bpm})$ & $95.55 \pm 15.14$ & $61-152$ \\
Respiratory rate (breaths/m) & $28.39 \pm 6.36$ & $18-40$ \\
Temperature (degree Celsius) & $36.26 \pm 0.48$ & $36-38$ \\
Oxygen saturation (\%) & $94.38 \pm 4.61$ & $75-98$ \\
\hline
\end{tabular}

Table 3. Distribution of patients according to the results of Revised Trauma Score (RTS), injury Severity Score (ISS) and the type of trauma.

\begin{tabular}{|c|c|c|c|c|}
\hline \multirow[t]{2}{*}{ Settings } & \multicolumn{3}{|c|}{ Revised Trauma Score } & \multirow[b]{2}{*}{ Total } \\
\hline & Thorax & Abdomen & Thoraco-abdominal & \\
\hline \multicolumn{5}{|c|}{ Number/Percentage } \\
\hline 12 & $8(12.69)$ & $12(19.04)$ & $13(20.63)$ & $33(52.38)$ \\
\hline 11 & $4(6.34)$ & $2(3.17)$ & $6(9.52)$ & $12(19.05)$ \\
\hline 10 & $1(1.59)$ & $4(6.34)$ & $1(1.59)$ & $6(9.52)$ \\
\hline 9 & $1(1.59)$ & $1(1.59)$ & $4(6.34)$ & $6(9.52)$ \\
\hline 8 & - & $1(1.59)$ & $4(6.34)$ & $5(7.94)$ \\
\hline 7 & - & - & $1(1.59)$ & $1(1.59)$ \\
\hline Total & $14(22.22)$ & $20(31.74)$ & $29(46.03)$ & $63(100)$ \\
\hline \multicolumn{5}{|c|}{ Injury Severity Score } \\
\hline \multicolumn{5}{|c|}{ Number/Percentage } \\
\hline Mild (1 - 9) & $8(12.69)$ & $5(7.93)$ & $6(09.52)$ & $19(30.15)$ \\
\hline Moderate $(10-15)$ & $1(1.59)$ & $2(3.17)$ & - & $3(04.76)$ \\
\hline Severe $(16-24)$ & $1(01.59)$ & $8(12.69)$ & $8(12.69)$ & $17(26.98)$ \\
\hline Critical $(\geq 25)$ & $4(06.34)$ & $5(7.93)$ & $15(23.80)$ & $24(38.09)$ \\
\hline Total & $14(22.22)$ & $20(31.74)$ & $29(46.03)$ & $63(100)$ \\
\hline
\end{tabular}

Table 4. Distribution of patients according to the effusions found on physical examination and the site of the emmergency (thoracic, abdominal and thoraco-abdominal) trauma.

\begin{tabular}{ccccc}
\hline \multirow{2}{*}{ Settings } & Thorax & Abdomen & Thoraco-abdominal & Total \\
\cline { 2 - 4 } & \multicolumn{4}{c}{ Number/Percentage } \\
\hline Pleural fluid & $02(3.17)$ & - & $1(1.59)$ & $3(4.76)$ \\
Peritoneal fluid & - & $3(4.76)$ & $8(12.69)$ & $11(17.46)$ \\
\hline
\end{tabular}




\section{Paraclinical data}

- Emergency EFAST ultrasound data

Completion time

The average time to complete the EFAST ultrasound was 7 minutes 2 seconds \pm 3 minutes 2 seconds with extremes of 05 to 20 minutes.

EFAST ultrasound results

Thirty-two patients $(50.79 \%)$ did not have a positive EFAST. Table 5 shows the distribution of patients according to the type of effusion found on EFAST and the site of the trauma. Figures 1-3 illustrate the effusions found on EFAST ultrasound in the various pleural and peritoneal cavities of the emergency room.

Results of standard radiographic and diagnostic thoracic ultrasound

Table 6 shows the distribution of lesions diagnosed on standard radiography and ultrasound. Figure 4 and Figure 5 show chest X-ray, facial incidence of a patient with chest and abdomen trauma on admission and 24 hours later.

Table 5. Distribution of patients according to the type of effusions found at E-FAST and the site of the emergency trauma.

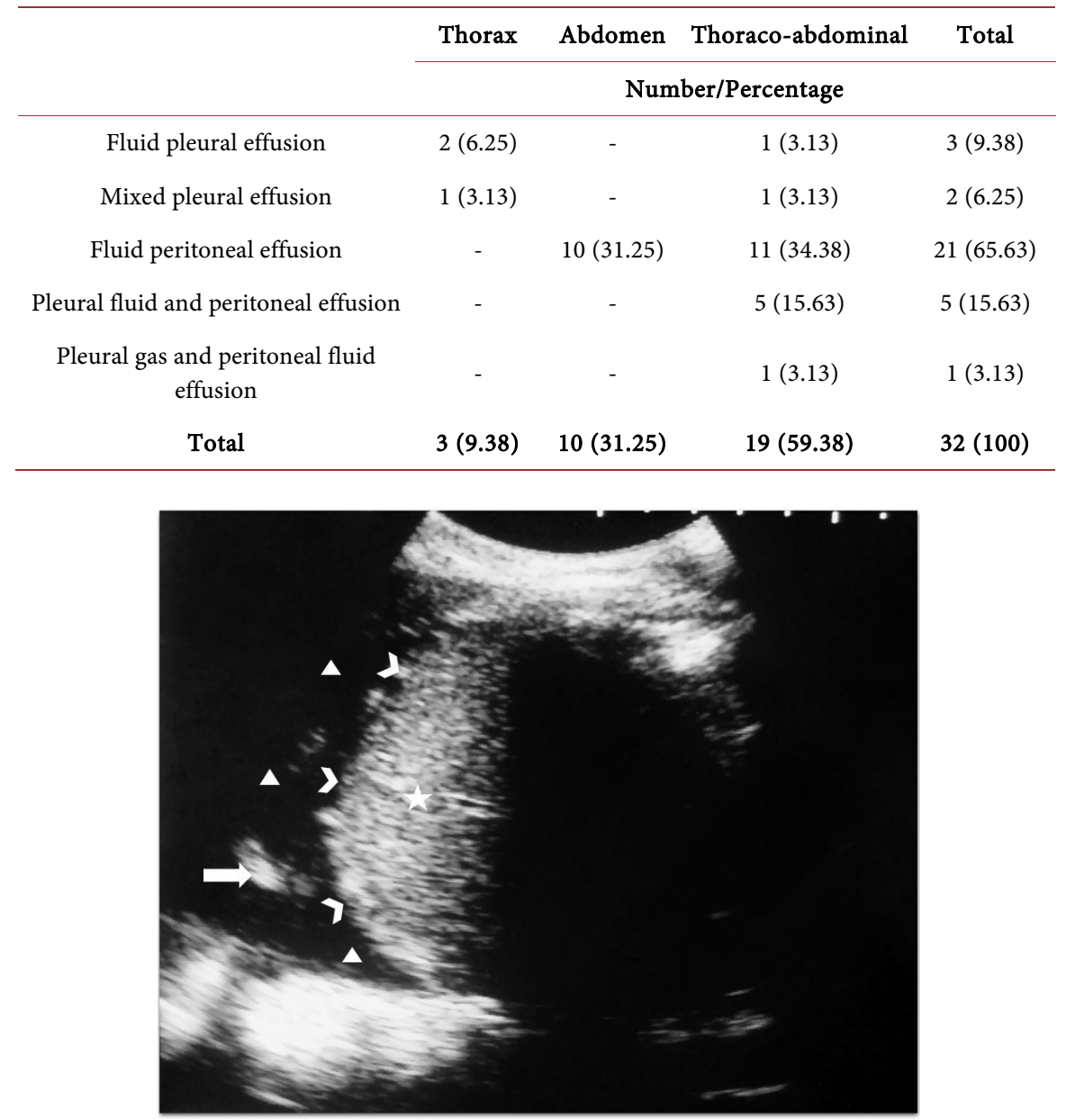

Figure 1. Fluid pleural effusion visualized on E-FAST ultrasound (Triangles) with contused lung tissue (arrow) in the right pleural cul-de-sac bounded at the bottom by the diaphragm (arrowheads) and the liver (Star). 


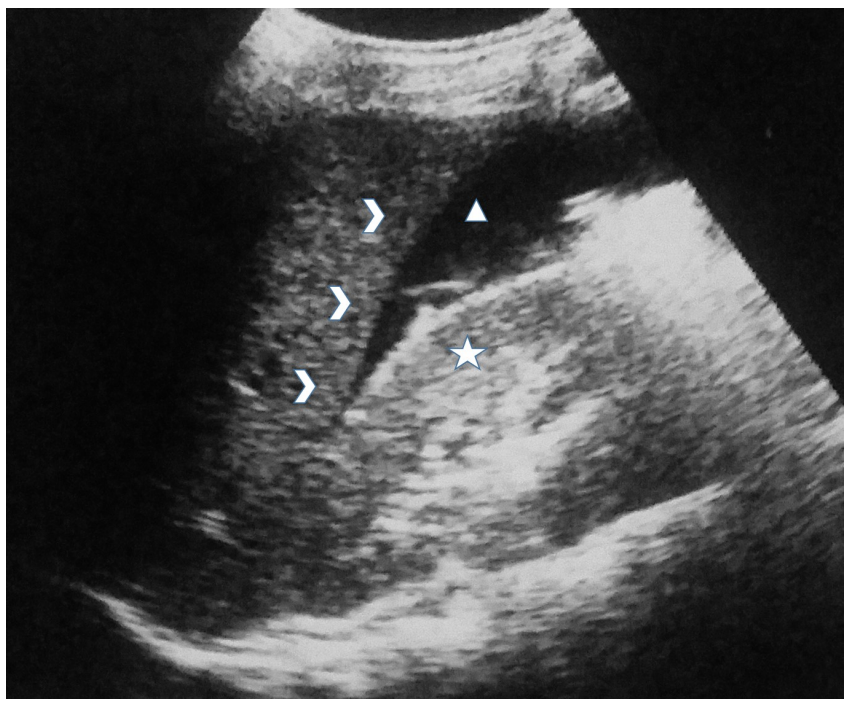

Figure 2. Peritoneal fluid effusion visualized on EFAST ultrasound, in Morrison's compartment (Triangle) between the liver (arrowheads) and the right kidney (Star).

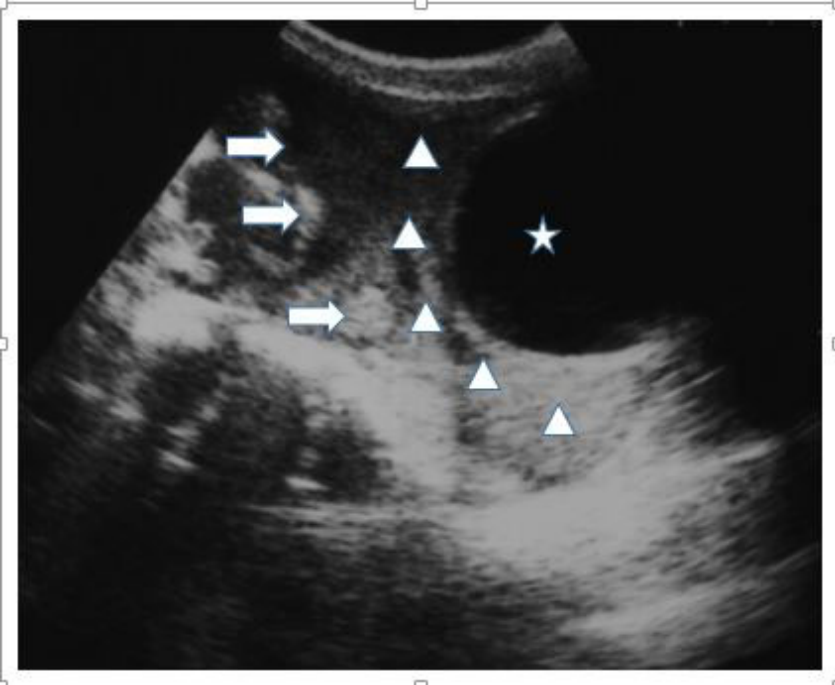

Figure 3. Peritoneal fluid effusion visualized on E-FAST ultrasound in the Douglas' cul-de-sac (triangles) with blood clots (arrows) behind the bladder (star).

Table 6. Distribution of lesions diagnosed on standard radiography and ultrasound.

\begin{tabular}{ccc}
\hline & Radiography & Ultrasound \\
\cline { 2 - 3 } Container damage & \multicolumn{2}{c}{ Number/Percentage } \\
Thoracic flap & $3(4.76)$ & - \\
Ribs fracture & $30(47.62)$ & - \\
Sternal fractures & - & $4(6.35)$ \\
Subcutaneous emphysema & $1(1.59)$ & $1(1.59)$ \\
Content damage & & $10(10.59)$ \\
Hemothorax & $3(4.76)$ &
\end{tabular}




\section{Continued}

\begin{tabular}{ccc}
\hline Hematocele & $1(1.59)$ & $1(1.59)$ \\
Pneumothorax & - & $3(4.76)$ \\
Pneumatocele & $2(3.17)$ & - \\
Lung contusions & $14(22.22)$ & $7(11.11)$ \\
\hline
\end{tabular}

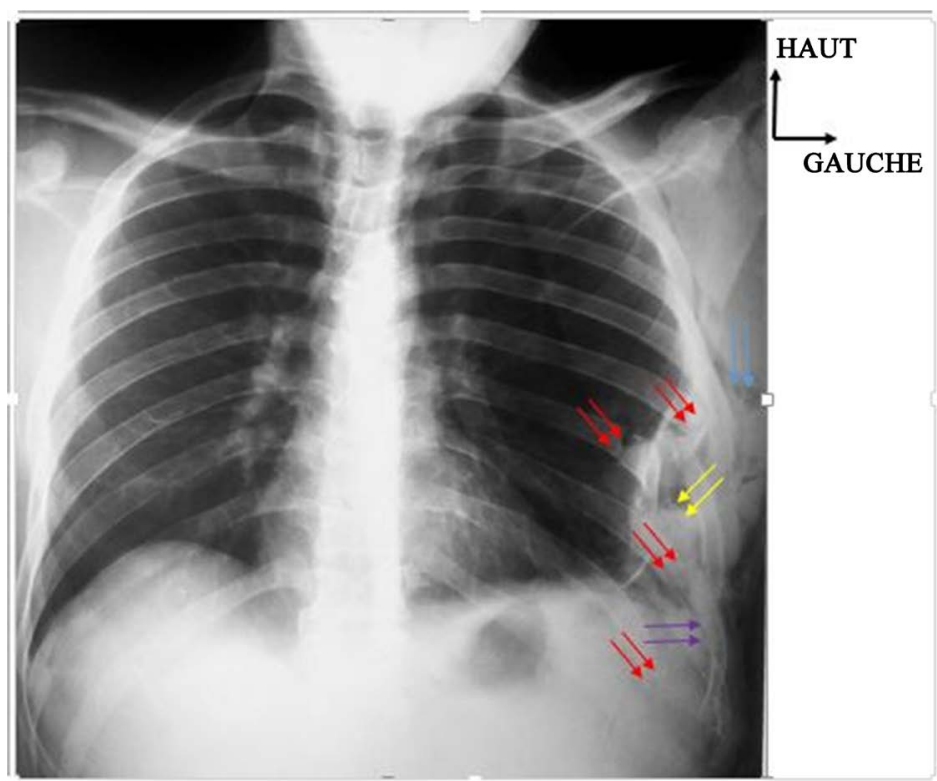

Redarrows: Rib fractures; Yellowarrows: Pneumatocele + pulmonary contusion; Blue arrows: Subcutaneousemphysema; Purple arrows: Effusion of the left pleural cul-de-sac

Figure 4. Chest $\mathrm{x}$-ray, frontal view of a patient with trauma to the thorax and abdomen on admission.

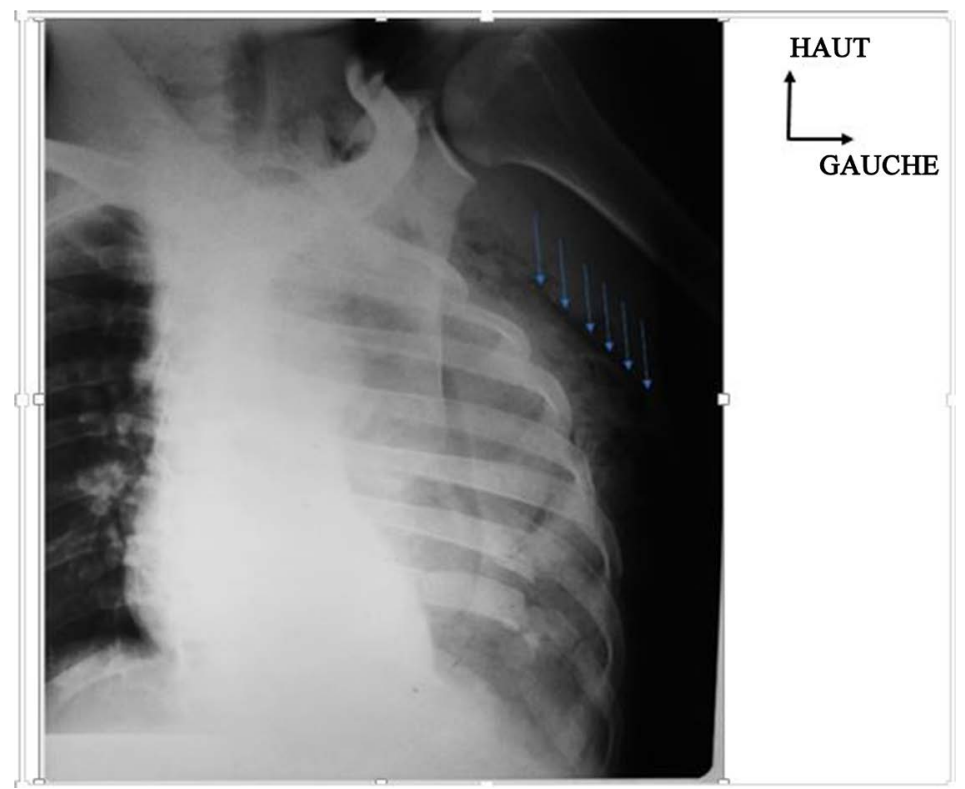

Blue arrows: Subcutaneousemphysema; Total opacity of the left pulmonary field: Hemothorax.

Figure 5. Chest x-ray, frontal view in decubitus position of the same patient as in Figure 5 twenty-four hourslater. 
Abdominal diagnostic ultrasound results

Abdominal ultrasound performed, made possible to objectify lesions in 25 patients among whom 21 trauma (84\%) had splenic lesion, 1 trauma (4\%) had liver injury and 3 trauma (12\%) had both splenic and liver injury.

\section{Biological assessments}

The mean hemoglobin level in chest trauma patients was $10.85 \pm 2.91 \mathrm{~g} / \mathrm{dl}$ with extremes of 07.80 and $12.50 \mathrm{~g} / \mathrm{dl}$. The mean hemoglobin level in abdominal trauma was $09.75 \pm 02.01 \mathrm{~g} / \mathrm{dl}$ with extremes of 04.70 and $12.90 \mathrm{~g} / \mathrm{dl}$.

The mean hemoglobin level in thoraco-abdominal trauma patients was 09.73 $\pm 2.07 \mathrm{~g} / \mathrm{dl}$ with extremes of 05.60 and $13.5 \mathrm{~g} / \mathrm{dl}$.

\section{Therapeutic data}

\section{Therapeutic decision}

Results of the first phase of the assessment of trauma patients.

Figure 6 shows the results of the first phase of the assessment of trauma patients.

\section{EFAST ultrasound results during monitoring}

Fifty-eight patients (84.12\%) were monitored. 5 unstable and EFAST negative patients were stabilized after resuscitation.

Figure 7 shows the results of the second phase of the assessment: 16 patients (27.58\%) presented secondarily an unstable hemodynamic state and a positive EFAST examination within an average of 07 hours and 30 minutes \pm 2 hours and 30 minutes with extremes of one hour and 20 hours. The 11 (18.96\%) EFAST

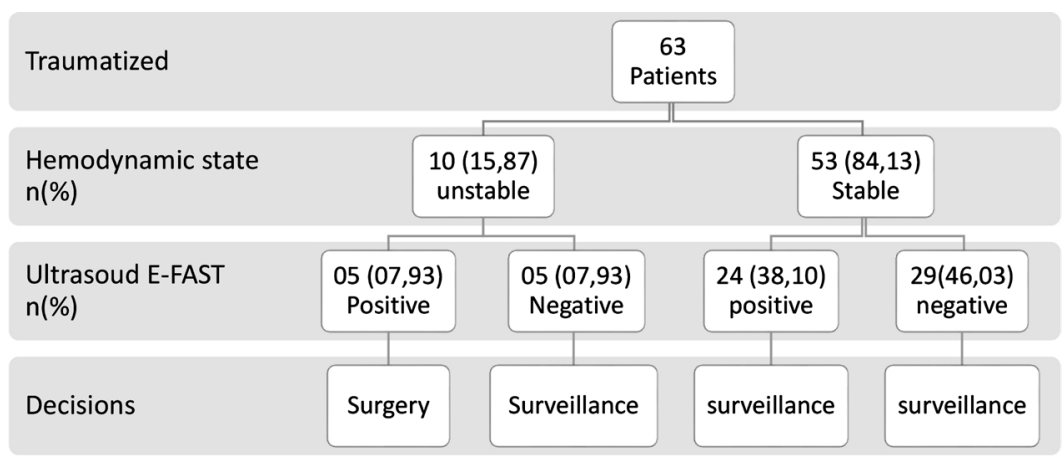

Figure 6. Results of the first phase of the assessment of trauma patients.

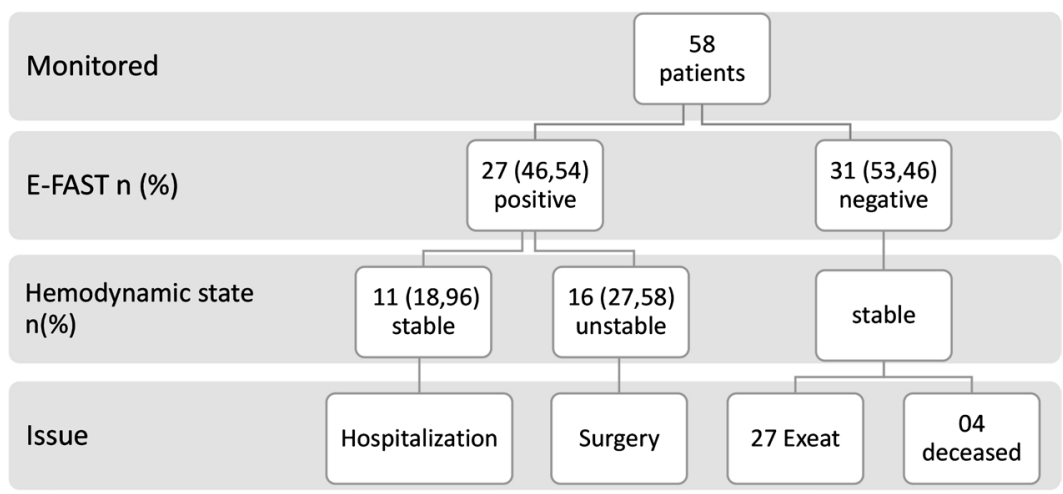

Figure 7. Results of the second phase of the assessment of trauma patients. 
positive patients with stable hemodynamics were transferred to hospital after 24 hours of monitoring and secondarily exeat.

\section{Surgical technique}

- Two (02) patients underwent pleural drainage.

- Eighteen (18) patients underwent laparotomy.

- One (1) patient underwent pleural drainage and laparotomy.

Time between completion of EVAST and surgical treatment

The average time taken to take charge of the 5 patients operated on in an emergency room was 03.46 hours \pm 02 hours with extremes of one hour $55 \mathrm{mi}$ nutes and 06 hours 25 minutes. The mean time to secondary management of 19 monitored patients who became unstable was 27.58 hours \pm 11.88 hours with extremes of 13 to 42 hours for pleural fluid effusions and 9.12 hours \pm 5.95 hours with extremes of 1 hour 45 minutes to $9 \mathrm{pm}$ for peritoneal fluid effusions.

\section{Peroperative diagnosis}

Table 7 shows the distribution of intra-abdominal lesions diagnosed on ultrasound.

\section{Contribution of EFAST ultrasound}

EFAST ultrasound and physical examination results.

Physical examination suspected pleural fluid effusion in 03 (04.71\%) patients, peritoneal fluid effusion in $11(17.46 \%)$ patients. No gaseous pleural effusion was found. Figure 8 shows the results the EFAST ultrasound and the physical examination.

Table 7. Distribution of intra-abdominal lesions diagnosed during surgery.

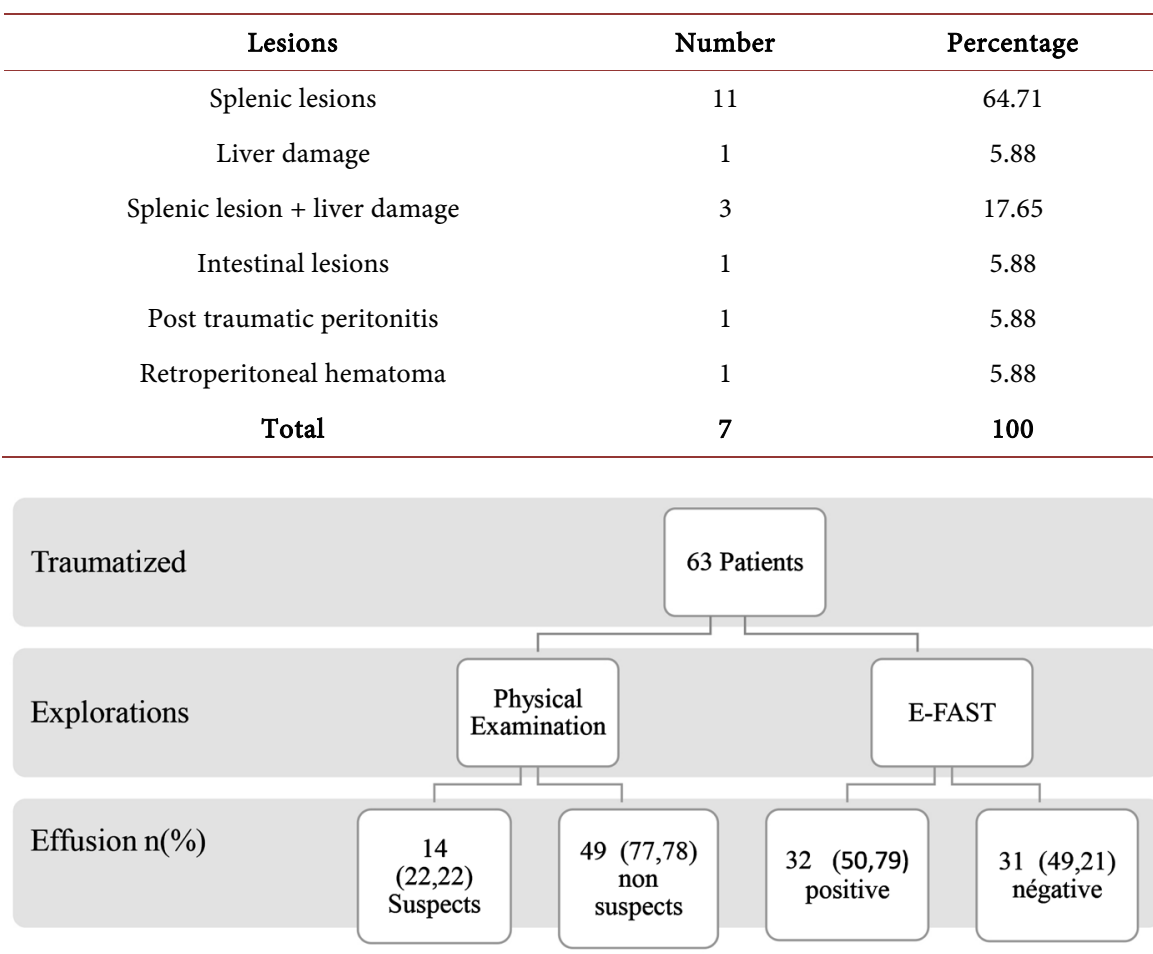

Figure 8. Physical examination results and EFAST results. 


\section{EFAST ultrasound performance}

The performance of the EFAST ultrasound was obtained by comparing the results of the EFAST ultrasound with those of laparotomy and pleural drainage.

-Performance of EFAST for the diagnosis of significant hemothoraxes

EFAST ultrasound was performed in 43 chest trauma patients. We found 03 true positives confirmed by pleural drainage, and 40 true negatives confirmed by radiography and clinical monitoring. The EFAST ultrasound is said to have a sensitivity of $100 \%$, a specificity of $100 \%$, a negative and positive predictive value of $100 \%$.

-Performances for the diagnosis of hemoperitins

EFAST ultrasound was performed in 49 patients with abdominal trauma. We found 24 true positives, 02 false positives confirmed by laparotomy which found digestive pus and juice as effusion. Similarly, we found 22 true negatives. The EFAST ultrasound is reported to have a sensitivity of $92.30 \%$, a specificity of $100 \%$, a negative predictive value of $92.30 \%$ and a positive predictive value of $100 \%$.

\section{Evolving data}

Of the 63 patients received, 06 deaths were recorded for a mortality rate of 09.52\%. Secondary bleeding was found on EFAST ultrasound on the second postoperative day in 02 patients who had received hepatic sutures. Table 8 shows the mortality of trauma patients based on the results of EFAST ultrasound.

\section{Discussion}

\section{Clinical data}

The method of direct admission of patients to the hospital from the place of the accident was the majority in our series (61.90\%) and this observation is identical to that of Tchaou et al. in 2013 who reported an equally high proportion in polytrauma victims (76.2\%) [22] [20]. Severity of the injuries could justify the patients' transfer to the nearest hospital from the accident site and better manage most of the injuries.

Fifty patients $(79.36 \%)$ consulted within 24 hours and $20.64 \%$ after 24 hours. The average time to consultation was 2.5 hours. This long consultation period, objectified in our sample, delays the treatment and could constitute a factor of

Table 8. Distribution of the evolution of trauma patients based on ultrasound results EFAST.

\begin{tabular}{|c|c|c|c|c|c|c|}
\hline & \multicolumn{4}{|c|}{ Ultrasound EFAST } & \multirow{3}{*}{$\begin{array}{c}\text { Total } \\
\text { (N) }\end{array}$} & \multirow{3}{*}{$\mathbf{P}$} \\
\hline & \multicolumn{2}{|c|}{ Positive } & \multicolumn{2}{|c|}{ Negative } & & \\
\hline & $\mathrm{n}$ & $\%$ & $\mathbf{n}$ & $\%$ & & \\
\hline Favorable & 30 & 47.63 & 27 & 42.86 & 57 & 0.4220 \\
\hline Death & 2 & 03.17 & 4 & 6.34 & 06 & \\
\hline TOTAL & 32 & 50.80 & 31 & 49.20 & 63 & \\
\hline
\end{tabular}


poor prognosis due to the extent of blood loss. Admissions after 24 hours are explained by the lack of a pre-hospital care system and the preference of patients to consult in a peripheral health facility or to indulge in self-medication because of their lack of financial means [20] and decide to consult in an appropriate center only in case of worsening of the clinical picture.

Non-medical means of transport were used in $93.65 \%$ for the victims. Four patients (6.45\%) received medical transportation. The chain of pre-hospital care being absent, patients were admitted to the emergency unit with multiple organ failure which worsened their clinical condition and sometimes made care difficult as financial resources are often not available. Yena et al. in Mali reported in a study on chest trauma that $75.6 \%$ of patients were transported by non-medical means. Several African authors have reported similar results [23] [26] [27].

Road accidents (68.25\%) and assaults (15.87\%) were the most common causes of trauma. In fact, accident injuries represent the second leading cause of death in the world [28]. The causes are multifactorial: an exponential increase in the number of cars and motorcycles in emerging countries, non-observance of basic road safety standards. In addition, the condition of the roads, their lack of night illumination, the promiscuity between various types of motorized vehicles, animals and pedestrians, rise the exposure to accidents [29]. Assaults are the second cause in our series and this is explained by the fact that Parakou is becoming more and more modernized, insecurity is also growing there as in any large metropolis. Our results are similar to those of Hossein et al in Iran who reported that road accidents are the main cause of thorax and abdomen trauma (51.7\%) followed by physical assaults (32.2\%) [5]. Ouchemi et al in Chad reported a similar result (51\% of road accidents) [30] as did Brooks et al in the UK [31].

\section{Paraclinical data}

\section{Contribution of EFAST ultrasound in the management \\ - Diagnostic delay}

In our series, the time to perform the EFAST ultrasound was 7 min 2 seconds \pm 3 min 2 seconds with extremes of $5 \mathrm{~min}$ and $20 \mathrm{~min}$, which allowed the surgeon to indicate an emergency operative act in $7.93 \%$ of our patients. Early diagnosis of effusions is useful in speeding up the management of trauma patients. Our results are close to those of Brenchley et al. in the United Kingdom (5 minutes) [32], Muller et al. in Congo (10 minutes) [25], Smith et al. in South Africa (10 minutes) [33]. According to a randomized study evaluating the results of the ultrasound performed in the emergency room in the emergency medicine department of the New York Methodist Hospital in Brooklyn (USA), a reduction in the time to initial diagnosis reciprocally leads to a reduction in the time it takes to pass the test at the emergency reception unit in the operating theater [34].

\section{- EFAST ultrasound results \\ Gaseous pleural effusions}

In our series, we objectified 6.97\% pleural gas effusions. Yassir Abdulrahman 
et al. in 2014 in Qatar in a study examining the utility of EFAST in the diagnosis of chest contusions reported $11 \%$ proportion of pleural gas effusions [17]. Mao Zhang et al. in Hangzhou in China objected to $21 \%$ pleural gas effusions in polytrauma victims [35]. Hamada et al. in 2016 at Kremlin-Bicetre in France, in a study on the integration of EFAST in the initial management of stable trauma patients reported $29 \%$ of pleural gas effusions [36]. These results are far above ours. This could be explained by the difference in research method and techniques. We used a 3.5 MHz abdominal convex probe in our study. This enquiry has low sensitivity for low abundance pneumothorax. On the other hand, these different authors, in addition to having used various convex and flat probes from 5 to $10 \mathrm{MHz}$, compared their results with those of chest scanner. This brings us back to the second bias of our study which called into question the quality of the equipment used. In order to have reliable results, our hospitals must be equipped with high-performance equipment. Furthermore, Sauter et al. in 2017 in a study on the practicality and limitations of EFAST in detecting pneumothorax reported that $59 \%$ of pneumothoraxes escaped EFAST but were found on CT [37].

\section{Pleural fluid effusions}

In our study, EFAST ultrasound revealed 23.25\% pleural fluid effusions. This result is close to those of Gülalp et al. in Turkey [38] and Smith et al. in South Africa in 2010 [33] who found proportions of $22 \%$ and $25 \%$ respectively. These results support the high incidence of post-traumatic pleural fluid effusions. Post-traumatic pleural fluid effusions are therefore to be feared when a patient admitted to the emergency room is suspected of chest trauma.

\section{Peritoneal fluid effusions}

In our study, we objectified $50.10 \%$ of peritoneal effusions. In a previous study on post-traumatic hemoperitoneum in 2010, Allodé et al. reported a proportion close to ours (43.44\%) [39] in Parakou. Similarly, Doussou et al. in 2014 in Cotonou reported a proportion of 41\% [17]. Ouchemi et al. in Chad in 2017 found a result lower than ours at $34.46 \%$ at the National Teaching Hospital of N'Djamena [30]. These figures remain worrying as they reflect the significance of the injuries observed, hence the need for rapid diagnosis and management in order to improve the prognosis of these patients.

\section{EFAST ultrasound and physical examination}

Physical examination found pleural fluid effusion in $03(04.71 \%)$ patients, peritoneal fluid effusion in $11(17.46 \%)$ patients. No gaseous pleural effusion was found. The EFAST ultrasound intended to be an extension of the emergency physician's hand and its ultrasound stethoscope, allows a better initial assessment of patients. This leads us to conclude that a systematic ultrasound of all trauma patients could increase the sorting performance of our emergency department.

\section{EFAST ultrasound and severity score}

The average ISS of EFAST positive patients was $29.43 \pm 11.47$ with extremes of 16 and 57 (P: 0.0005). The presence of an effusion is associated with serious 
condition and should require patients to be under equipped surveillance. This significant link has been found by other authors such as Gülalp et al. in Turkey [84], Hamada et al. in France, Beck-Razi et al. in Lebanon [40], Skerritt et al. in London [41].

\section{EFAST ultrasound, treatment decision and time to treatment}

In our series, $7.93 \%$ of patients were treated urgently for positive EFAST and hemodynamic instability within a mean period of $3.46 \pm 2$ hours, and $27.58 \%$ received secondary surgery after ultrasound monitoring in a delay of 9.12 hours \pm 5.95 hours (hemoperitoneum) and 27.58 hours \pm 11.88 hours (hemothorax). The question of reducing the time before surgery seems important, the concept of "Golden Hour" or "golden hour" used in surgery is characterized by the crucial need to take care of trauma patients. Morbidity and mortality are affected if care is not instituted within the first hour of trauma. This concept justifies our current trauma system [42]. Melniker et al. have shown in a randomized study on the performance of ultrasound in emergency rooms that FAST exam can reduce the time to surgery. Patients who received FAST examination had $64 \%$ reduction in surgical intervention time [34].

The fact that the patient goes to the operating theater straightaway is discussed by several authors who wonder if surgery in this case is appropriate or if the operating time would not be lengthened due to the absence of a definitive and specific diagnosis. It is possible that patients will be better treated if their admission in the operating room is delayed in favor of a definitive diagnosis [43]. It would be difficult in our context to comply with this point of view since our hospitals suffer from the lack of diagnostic equipment, particularly scanner. The diagnosis of intrathoracic and abdominal lesions is reduced to the simple performance of a standard X-ray and ultrasound in $20 \%$ to $30 \%$ of cases. The latter are still depend on the patient's financial means [21] [22] [23]. The delay in treatment would not allow us to have an accurate diagnosis. In this context, EFAST ultrasound would find its role as a sorting tool allowing to determine that a significant proportion of patients (51.79\% positive in our series) needs a rapid decision and an appropriate monitoring. Moreover, non-surgical management is becoming the treatment modality for visceral trauma choice in a hemodynamically stable patient [43]. In our series, $18.93 \%$ of EFAST positive patients were removed without operative treatment. EFAST would therefore allow more careful management of patients and offer the possibility of a complete diagnostic workup.

\section{Interest of EFAST ultrasound in patient monitoring}

Advance Trauma Life Support (ATLS) guidelines indicate that EFAST ultrasound should be performed immediately after initial clinical examination [28]. But we decided to extend our assessment over 24 to 48 hours, as did Smith et al. in 2014 in South Africa in hemodynamically stable patients [44]. Our results and theirs show that a high proportion (27.58\% and $33.33 \%$ respectively) of EFAST negative patients at the first evaluation, were positive beyond 24 hours of moni- 
toring outside the ATLS time frame. The systematic performance of surveillance using EFAST ultrasound appears to be of great interest. Pons et al. in Paris in 2012 in a study on the value of a second EFAST ultrasound during the initial management of a patient with suspected polytrauma came to the same conclusion [45]. In addition, we found two postoperative bleeds after ultrasound monitoring.

\section{Conclusion}

This study on the contribution of EFAST ultrasound in the management of blunt thoracic and abdominal traumas in Parakou allowed us to conclude that blunt thoracic and abdominal traumas are frequent and affect many people more young adults between 20 years and 40 years with a male predominance. They are mainly due to accidents on public roads. The introduction of EFAST-type ultrasound in a resource-constrained medical environment is both desirable and feasible. In this study, the use of EFAST ultrasound had an important influence on the decision-making process, allowing immediate triage of trauma patients for laparotomy, chest tube placement or armed clinical monitoring. The performance of the EFAST ultrasound, in terms of sensitivity, specificity, positive predictive value and negative predictive value allows its use in situations of deprivation.

\section{Conflicts of Interest}

The authors declare no conflicts of interest regarding the publication of this paper.

\section{References}

[1] Mefire, A.C., Pagbe, J.J., Fokou, M., Nguimbous, J.F., Guifo, M.L. and Bahebeck, J. (2010) Analysis of Epidemiology, Lesions, Treatment and Outcome of 354 Consecutive Cases of Blunt and Penetrating Trauma to the Chest in an African Setting. South African Journal of Surgery, 48, 90-93.

[2] Khan, I.A., Ghaffar, S., Asif, S., Ziaur, R., Asad, S., Ahmed, E., et al. (2009) Management of Thoracic Trauma: Experience at Ayub Teaching Hospital, Abbottabad. Journal of Ayub Medical College Abbottabad, 21, 152-154.

[3] Veysi, V.T., Nikolaou, V.S., Paliobeis, C., Efstathopoulos, N., Giannoudis, P.V., Infirmary, B.R., et al. (2009) Prevalence of Chest Trauma, Associated Injuries and Mortality: A Level I Trauma Centre Experience. International Orthopaedics, 33, 1425-1433. https://doi.org/10.1007/s00264-009-0746-9

[4] Huda, F., Sah, D. and Singh, K. (2011) Pattern of Abdominal Injuries in a Tertiary Care Centre on N.H. 24 in Western U.P. New Indian Journal of Surgery, 2, 7-14.

[5] Hemmati, H., Kazemnezhad-leili, E., Mohtasham-amiri, Z., Dar, A.A., Davoudi-kiakalayeh, A., Dehnadi-moghaddam, A., et al. (2013) Evaluation of Chest and Abdominal Injuries in Trauma Patients Hospitalized in the Surgery Ward of Poursina Teaching Hospital, Guilan, Iran. Archives of Trauma Research, 1, 160-165. https://doi.org/10.5812/atr.7672

[6] Salah, M. and Ammar, B.E.N. (2003) Le polytraumatise. 3rd Edition, CPU, Paris, 
$832 \mathrm{p}$.

[7] Rozycki, G.S., Ochsner, M.G., Schmidt, J.A., Frankel, H.L., Davis, T.P., Wang, D. and Champion, H.R. (1995) A Prospective Study of Surgeons-Performed Ultrasound as the Primary Adjuvant Modality for Injured Patient Assessment. The Journal of Trauma, 39, 492-498. https://doi.org/10.1097/00005373-199509000-00016

[8] Meuli, R.A. and Schnyder, P. (1993) Radiologie des traumatismes fermés du thorax. Feuillets de Radiologie, 33, 265-275.

[9] Friedamn, P.J. (1985) Adult Pulmonary Ligament Pneumatocele: A Loculated Pneumothorax. Radiology, 155, 575-576. https://doi.org/10.1148/radiology.155.3.4001354

[10] Voiglio, E.J. and Passot, G. (2011) Traumatisme abdominal fermé Stratégie de prise en charge diagnostique et thérapeutique. Urgencepratique $N^{\circ}$ Spécial Urgences Traumatologiques, 108, 47-51.

[11] Taourel, P., Merigeaud, S., Millet, I., Hoquet, M.D., Lopez, F.M. and Sebane, M. (2008) Traumatisme thoraco-abdominal: Stratégie en imagerie. Journal of Radiology, 89, 1833-1854. https://doi.org/10.1016/S0221-0363(08)74490-1

[12] Scalea, T.M., Rodriguez, A., Chiu, W.C., et al. (1999) Focused Assessment with Sonography for Trauma (FAST): Results from an International Consensus Conference. The Journal of Trauma, 46, 466-472. https://doi.org/10.1097/00005373-199903000-00022

[13] Kirkpatrick, A.W., Sirois, M., Laupland, K.B., et al. (2004) Hand-Held Thoracic Sonography for Detecting Post-Traumatic Pneumothoraces: The Extended Focused Assessment with Sonography for Trauma (EFAST). The Journal of Trauma, 57, 288-295. https://doi.org/10.1097/01.TA.0000133565.88871.E4

[14] Rowan, K.R., Kirkpatrick, A.W., Liu, D., Forkheim, K.E., Mayo, J.R. and Nicolaou, S. (2002) Traumatic Pneumothorax Detection with Thoracic US: Correlation with Chest Radiography and CT-Initial Experience. Radiology, 225, 210-214. https://doi.org/10.1148/radiol.2251011102

[15] Caiulo, V.A. (2011) Point-of-Care Ultrasonography. New England Journal of Medicine, 364, 749-757. https://doi.org/10.1056/NEJMra0909487

[16] Société Francaise de Médecine d’Urgences (2013) Échographie en médecine d'urgence: Quel bénéfice pour le patient? https://echourgences.files.wordpress.com/2014/11/refsfmu2013querelou.pdf

[17] Abdulrahman, Y., Musthafa, S., Hakim, S.Y., Nabir, S., Qanbar, A., Mahmood, I., et al. (2014) Utility of Extended FAST in Blunt Chest Trauma: Is It the Time to Be Used in the ATLS Algorithm? World Journal of Surgery, 39, 172-178. https://doi.org/10.1007/s00268-014-2781-y

[18] Richards, J.R. and Mcgahan, J.P. (2017) Focused Assessment with Sonography in Trauma (FAST) in 2017: What Radiologists Can Learn. Radiology, 283, 30-48. https://doi.org/10.1148/radiol.2017160107

[19] Ferrada, P., Evans, D., Wolfe, L., Anand, R.J., Vanguri, P., Mayglothling, J., et al. (2014) Findings of a Randomized Controlled Trial Using Limited Transthoracic Echocardiogram (LTTE) as a Hemodynamic Monitoring Tool in the Trauma Bay. Journal of Trauma and Acute Care Surgery, 76, 31-38. https://doi.org/10.1097/TA.0b013e3182a74ad9

[20] Tchaou, B.A., Assouto, P., Hodonou, M., Afouncho, C.A. and Aguemon, A.R. (2013) Prise en charge des polytraumatisés à l'hôpital universitaire de Parakou au Bénin. RAMUR, 17, 1-10. 
[21] Sambo, B.T., Hodonou, A.M., Allode, A.S., Mensah, E., Youssouf, M. and Menhinto, D. (2016) Aspects Épidémiologiques, Diagnostiques Et Thérapeutiques Des Traumatismes Abdominaux À Bembéréké-Nord Bénin. European Scientific Journal, 12, 395-405. https://doi.org/10.19044/esj.2016.v12n9p395

[22] Fanomezantsoa, R., Davidà, R.S., Tianarivelo, R. and Fabienne, R.L. (2015) Traumatismes fermés et pénétrants de l'abdomen: Analyse rétrospective sur 175 cas et revue de la littérature. The Pan African Medical Journal, 20, Article 129. https://doi.org/10.11604/pamj.2015.20.129.5839

[23] Rakotoarivony, S.T., Rakotomena, S.D. and Randriamiarana, J.M. (2008) Aspects épidémiologiques des traumatismes abdominaux par accident de circulation au Centre Hospitalier Universitaire d'Antananarivo. Revue Tropicale de Chirurgie, 2, $18-21$.

[24] Dossou, F.M., Allode, S.A., Gbessi, D.G., Hounkpe, P.C., Biao, M.A., Yevide, B., et al. (2014) Ponction Peritoneale Transparietale (PPT) dans le diagnostic des contusions abdominales de l'adulte en milieu sous-equipe. J Afr Chir Digest, 14, 1645-1650.

[25] Muller, M.M., Salmon, M., Salmon, C., Malemo, M., Wendel, S.K., Ruhangaza, C., et al. (2015) Utilisation of Focused Assessment with Sonography for Trauma (FAST) in a Referral Hospital in an Acute Conflict Zone. African Journal of Emergency Medicine, 5, 7-11. https://doi.org/10.1016/j.afjem.2014.09.003

[26] Mutter, D., Russier, Y., Schmidt-Mutter, C. and Marescaux, J. (1998) Contusions et plaies de l'abdomen. Encycl. Méd. Chir. (Elsevier, Paris), Gastro-entérologie, 9007-A-10, Urgences, 24-100-B-30, 12 p.

[27] Collège National des Enseignants de Réanimation (2012) Réanimation et urgences. 4th Edition, Elsevier Masson SAS, Amsterdam, 377 p.

[28] Kool, D.R. and Blickman, J.G. (2007) Advanced Trauma Life Support ${ }^{\oplus}$. ABCDE from a Radiological Point of View. Emergency Radiology, 14, 135-141. https://doi.org/10.1007/s10140-007-0633-X

[29] Peden, M., Scurfield, R. and Sleet, D. (2004) Rapport mondial sur la prévention des traumatismes dus aux accidents de la circulation. Organisation Mondiale de la Santé, Genève.

[30] Choua, O., Rimtebaye, K., Yamingue, N., Moussa, K. and Kaboro, M. (2017) Aspects des traumatismes fermés de l'abdomen opérés à l'Hôpital Général de Référence Nationale de N'Djaména (HGRN), Tchad: A propos de 49 cas. The Pan African Medical Journal, 26, 50. https://doi.org/10.11604/pamj.2017.26.50.8327

[31] Brooks, A., Davies, B., Smethhurst, M. and Connolly, J. (2004) Prospective Evaluation of Non-Radiologist Performed Emergency Abdominal Ultrasound for Haemoperitoneum. Emergency Medicine Journal, 21, e5. https://doi.org/10.1136/emj.2003.006932

[32] Brenchley, J., Walker, A., Sloan, J.P., Hassan, T.B., et al. (2006) Evaluation of Focused Assessment with Sonography in Trauma (FAST) by UK Emergency Physicians. Emergency Medicine Journal, 23, 446-448.

https://doi.org/10.1136/emj.2005.026864

[33] Smith, Z.A., Postma, N. and Wood, D. (2010) FAST Scanning in the Developing World Emergency Department. South African Medical Journal, 100, 105-108. https://doi.org/10.7196/SAMJ.3821

[34] Melniker, L.A., Briggs, W.M. and Mancuso, C.A. (2006) Randomized Controlled Clinical Trial of Point-of-Care, Limited Ultrasonography for Trauma in the Emergency Department: The First Sonography Outcomes Assessment Program Trial. Annals of Emergency Medicine, 48, 227-235. 
https://doi.org/10.1016/j.annemergmed.2006.01.008

[35] Zhang, M., Liu, Z.-H., Yang, J.-X., Gan, J.-X., Xu, S.-W., You, X.-D., et al. (2006) Rapid Detection of Pneumothorax by Ultrasonography in Patients with Multiple Trauma. Critical Care, 10, R112. https://doi.org/10.1186/cc5004

[36] Hamada, S.R., Delhaye, N., Kerever, S., Harrois, A. and Duranteau, J. (2016) Integrating eFAST in the Initial Management of Stable Trauma Patients: The End of Plain Film Radiography. Annals of Intensive Care, 6, 62. https://doi.org/10.1186/s13613-016-0166-0

[37] Sauter, T.C., Hoess, S., Lehmann, B., Exadaktylos, A.K. and Haider, D.G. (2017) Detection of Pneumothoraces in Patients with Multiple Blunt Trauma: Use and Limitations of eFAST. Emergency Medicine Journal, 34, 568-572. https://doi.org/10.1055/s-0036-1587758

[38] Betül, G., Karagün, Ö., Belli, S., Tufan, K., Özalay, M., et al. (2011) Use of Focused Assessment with Sonography in Trauma in Emergency Department Patients for Triage, Diagnosis and Disposition: A Series of Cases. JAEM, 10, 119-122. https://doi.org/10.5152/jaem.2011.025

[39] Allode, S.A., Olory-Togbé, J.L., Mensah, E., et al. (2011) Traumatismes abdominaux au C.H.D.U-P: Aspects Epidémiologiques et lésionnels. Annales de Puniversité de Parakou Série: Sciences de la Santé, 2, 41-51.

[40] Beck-razi, N., Fischer, D., Michaelson, M., Engel, A. and Gaitini, D. (2007) The Utility of Focused Assessment with Sonography for Trauma as a Triage Tool in Multiple-Casualty. Journal of Ultrasound in Medicine, 26, 1149-1156.

https://doi.org/10.7863/jum.2007.26.9.1149

[41] Skerritt, C., Haque, S. and Makin, E. (2014) Focused Assessment with Sonography in Trauma (FAST) Scans Are Not Sufficiently Sensitive to Rule Out Significant Injury in Pediatric Trauma Patients. Open Journal of Pediatrics, 4, 236-242. https://doi.org/10.4236/ojped.2014.43031

[42] Lerner, E.B. and Moscati, R.M. (2001) The Golden Hour: Scientific Fact or Medical "Urban Legend"? Academic Emergency Medicine, 8, 758-760. https://doi.org/10.1111/j.1553-2712.2001.tb00201.x

[43] Boese, C.K., Hackl, M., Müller, L.P., Ruchholtz, S., Frink, M. and Lechler, P. (2015) Nonoperative Management of Blunt Hepatic Trauma: A Systematic Review. Journal of Trauma and Acute Care Surgery, 79, 654-660. https://doi.org/10.1097/TA.0000000000000814

[44] Smith, Z.A. and Wood, D. (2014) Emergency Focused Assessment with Sonography in Trauma (FAST) and Haemodynamic Stability. Emergency Medicine Journal, 31, 273-277. https://doi.org/10.1136/emermed-2012-202268

[45] Pons, A. (2012) Intérêt d'une deuxième FAST (Focused Assessment with Sonography for Trauma) lors de la prise en charge initiale du patient suspect de polytraumatisme. Mémoire de DES d'Anesthésie-Réanimation. Académie de Paris, Paris, $36 \mathrm{p}$. 